\title{
Violence against health care workforce in COVID and non COVID times: Analysis of predisposing factors
}

Neeraj Garg ${ }^{1}$, Ruchi Garg ${ }^{2}$, Devender Kumar Sharma ${ }^{3}$, Shakti Kumar Gupta ${ }^{4}$, Puja Dudeja ${ }^{5}$

${ }^{1} \mathrm{MHA}$ (AlIMS), Armed Forces Medical College, Pune; ${ }^{2} \mathrm{MHA}$ (AIIMS), Mahatama Gandhi University of Medical Science and Technology, Jaipur; ${ }^{3} \mathrm{MHA}$ (AIIMS), All India Institute of Medical Sciences New Delhi; ${ }^{4} \mathrm{MHA}$ (AIIMS), All India Institute of Medical Sciences New Delhi; ${ }^{5} \mathrm{MD}$, Ph D Army College of Medical Sciences, New Delhi

\begin{tabular}{|c|c|c|c|c|c|c|c|}
\hline Abstract & Introduction & Methodology & Results & Conclusion & References & Citation & Tables / Figures \\
\hline \multicolumn{8}{|c|}{ Corresponding Author } \\
\hline \multicolumn{7}{|c|}{$\begin{array}{l}\text { Dr Puja Dudeja, Professor, Army College of Medical Sciences, New Delhi } 110010 \\
\text { Email id: puja dudeja@yahoo.com }\end{array}$} & 回语回 \\
\hline
\end{tabular}

\section{Citation}

Garg N, Garg R, Sharma DK, Gupta SK, Dudeja P. Violence against health care workforce in COVID and non COVID times: Analysis of predisposing factors. Indian J Comm Health. 2020;32(4):659-664. https://doi.org/10.47203/IJCH.2020.v32i04.009

Source of Funding: Nil Conflict of Interest: None declared

\section{Article Cycle}

Received: 12/09/2020; Revision: 21/11/2020; Accepted: 05/12/2020; Published: 31/12/2020

This work is licensed under a Creative Commons Attribution 4.0 International License.

\section{Abstract}

Background: The prevalence of violence against Health Care Workers (HCW) is showing a rising trend. Various studies have been done in the recent past shows that the prevalence of violence against HCW s ranged from $27.4 \%$ to $67 \%$. The present study was done to compare and analyze the underlying causes of violence against $\mathrm{HCW}$ in a Non COVID and COVID situation to identify the commonality if any, and to suggest any remedial measures. Methodology: This was cross-sectional analytical design and was carried out in inpatient care areas of a tertiary care hospital. The study subjects comprised of Doctors, Nurses, Group C employees. Data was collected using direct interview method on a standard questionnaire. In addition, various media reports were collected and analyzed through internet. Results: Maximum incidents were experienced in emergency and OPD, where staff patient's ratio is less. 39.4\% incidents were experienced by the staff who were providing care to the Terminally ill patients, Mentally and Physically disabled persons \& Psychiatric patients. Suggestion which emerged to reduce WPV are, triage in casualty, availability of trained security guards, CCTV, restricted visiting hours and limited attendants with the patients, improvement in patient amenities etc. Whereas in COVID situation the major reason is the religious and social belief, poor dietary services and lack of hygiene and sanitation. Conclusion: There is an urgent and inescapable requirement that the healthcare administrators should address the underlying precipitating factors of violence, for delivery of quality healthcare services to the patients in a safe environment.

\section{Keywords}

COVID Warriors, Predisposing Factors, Workplace Violence

\section{Introduction}

The Occupational Health and Safety (OHS) Regulation, section 4.27, defines violence in health sector as "the attempted or actual exercise by a patients/attendants other than a worker, of any physical force so as to cause injury to a worker."(1)
The prevalence of violence against healthcare workers is showing a rising trend. Every day there are some episodes of violence against this human resource in some part of the country. Patients experience extreme emotional, financial as well as physical stress when their near and dear ones are admitted in the hospitals. At times they lose control 
and act aggressively towards health care staff working there (2)

Various studies have been done in the recent past to assess the burden of violence against healthcare workers in India and abroad. The prevalence of physical violence against healthcare workers ranged from $3 \%$ to $17 \%$, while verbal abuse $27.4 \%$ to $67 \%(3)$. Such incidences of violence in medical profession are still been reported, when the humanity is facing one of the deadliest diseases ever been faced by the mankind. When on one hand the healthcare workers have been termed as health care warriors as they are risking their own lives to ensure uninterrupted care and treatment of COVID 19infected patients on the other hand there are few antisocial elements that are still targeting these personnel. Several healthcare workers in India have been attacked as they battle to stop the spread of the coronavirus. Reports say doctors have been spat at and chased away from homes (4) The same is creating an environment of threat and fear among the providers of healthcare as well creating problems for the administrators to motivate the healthcare workers to work under such challenging situation at the cost of their own safety and security.

In the current scenario it is imperative to assess the underlying causes of such violent incidences against healthcare workers. It is highly pertinent to assess various factors which lead to an act of violence against a healthcare worker in a Non COVID situation and the present scenario of COVID 19 cases. Despite risk to their own safety and security medical and paramedical staff is providing the healthcare services to the community however the irony is that there are instances reported where these healthcare providers are been attacked and threatened by the patients or their relatives or the community in general.

\section{Aims \& Objectives}

To assess the underlying causes of violence against healthcare workers in a Non COVID and COVID situation to identify the commonality if any, and to suggest any remedial measures.

\section{Material \& Methods}

This study was cross-sectional analytical design and was carried out in inpatient care areas of the hospital like Wards, Emergency department, Operation Theater, Intensive Care Unit, Daycare center etc. of a tertiary care government hospital of Western India. The study population included Doctors, Nurses, Group C (technicians, drivers, security staff housekeeping wards boys etc.) working in the hospital. The sample size was calculated by anticipating prevalence of every potential risk factor as $50 \%$, confidence level as $95 \%$ and precision as $10 \%$ (Absolute) minimum of 100 subjects were required ( i.e. Doctors $=100$, Nurses $=100$ and Group $C=100$ ). data was collected using a standard questionnaire as study tool that was adapted from a standardized questionnaire designed collaboratively in 2003 by the International Labor Office (ILO), the World Health Organization (WHO), the International Council of Nurses (ICN), and the Public Service International (PSI) (5). The same questionnaire has been used in the earlier studies also. (6) The questionnaire was translated into Hindi without any modification with back translation. Descriptive statistics were completed relating to the respondents' characteristics. Cronbach's alpha was performed after the data collection to measure reliability and internal consistency. Cronbach's alpha score was more than 0.8 . The following information was gathered from this tool:

- Predisposing factors of workplace violence against HCWs at hospital

- Safety measures adopted in the workplace for prevention of violence against HCW.

Written consent was also obtained from participants after explaining the aim and assuring the confidentiality of the study after information collected from the study participants.

Descriptive statistics were completed relating to the respondents' characteristics. Data were entered in MS Excel. Pearson's chi-square /Fisher exact test analysis was used to testing the differences in exposure to violence (physical and non-physical violence) according to respondents' characteristics. In case of scales, Kruskal-Wallis test was applied to see the difference between doctors, nurses \& group $C$ responses. Data were analyzed using SPSS version 20 . The $p$ value $<0.05$ was considered statistically significant in the analysis.

Data Collection in COVID Situation: In the current scenario it was not feasible to take the personal interviews with the stakeholders because of the strict lockdown measures imposed by the Govt as well as the risk of spreading the virus. Thus In-depth telephonic interviews were taken with various stakeholders ( $n=395)$ Each interview lasted for a minimum duration of 45 minutes. The interview was taken after prior appointment to have minimum interruption during data collection, in addition 
various media reports were collected and analyzed through internet and print and electronic media. The data was collated on the excel and analyzed with SPSS.

\section{Results}

It was revealed from the study that maximum incidents were reported / experienced by the HCW who are posted in emergency followed by wards and OPD (Table 1)

Major areas for violence in hospital as per reported incidents identified (Figure1).It has been observed that prevalence of WPV is more in which staff patient's ratio is less. Staff patient ratio in casualty and OPD is 1:50, \&1:30 respectively prevalence of violence in casualty and OPD is $47.5 \%$ and $40.5 \%$ respectively. Statistically significant difference in prevalence of violence in casualty as compared to ward with $P$ value. 002

Majority (73\%) of HCWs could not remember the day when they have faced WPV but in $15 \%$ out of remaining $27 \%$ were remembered that it was on Monday(Figure 2). Which further reflects that one of the major causes of violence is increased workload, which is more on Mondays as compared to other weekdays.

Study reveals that maximum $39.4 \%$ incidents were experienced by the staff who were providing care to the Terminally ill, Mentally and Physically disabled persons \& Psychiatric patients,(7) (Figure 3).It is observed that Prevalence of WPV is maximum during morning shifts.

Though it is not statistically significant but it was observed that risk of WPV is higher in persons who work in shifts i.e. $72.1 \%$ and those who are directly in contact with patients \& their attendants like doctors, nurses with Patientcare, nursing orderly are have experienced more violence (81.62\%) as compared to technicians, data operators, receptionists who are not in direct physical contact with patients (18.38\%).)

Second part of questionnaire had open ended questions on preventive measure to stop violence in health care organizations. They have given their suggestions like:

- Triage should be there in casualty.

- Trained male and female security guards round the clock to handle these situations should be be appointed in high risk areas like OPD and casualtity.
- CCTV should be installed in casualty, OPD, wards at entry \& exit point.

- Visiting hours should be fixed and limited attendants should be permitted to accompany the patients.

- Improvement in surrounding infrastructure like proper lighting at work station, privacy to the patients, cleanliness, noise control, availability of drinking water and food for the attendants.

- There should be some workshops on stress management \& meditation session for the staff working in $\mathrm{HCOS}$

(a) Thus, the major underlying causes of violence in Non COVID situation. (Figure 4)

I. Over crowding

II. Deteriorating medical condition of the patient (specially in cancer patients)

III. Poor amenities for patients and relatives

IV. Lack of security staff

V. Poor soft skill among healthcare workers

(b) Major underlying causes of violence in COVID situation. (Figure 5)

I. Religious and cultural belief of the patients (40\%)

II. Poor dietary services (25\%)

III. Poor amenities for patients and relatives (20\%)

IV. Lack of security staff (10\%)

V. Poor soft skill among healthcare workers (5\%)

\section{Discussion}

There are multiple factors affecting violence against health care workforce. these can be patient related (seriousness of illness, financial and social status of the family, etc.), doctor related (poor soft skills, lack of communication, increase work load, fatigue due to long working hours), environment related (poor facilities, rush, lack of security, lackadaisical attitude of administrators etc.)

Violence against doctors, nurses and on other staff isa burning issue for health care administrators hence needs more attention by the administrators. It was found that male staff(63.2\%) were more likely than female staff (37\%) to experience WPV and it is also supported by the other studies which shows that " Males' significantly experienced higher exposure to physical violence in comparison with females" (8). It was also found in other studies that male nursing staff were nearly twice as likely as female staff to be injured and nearly three times as likely to receive containment-related injuries $(9,10)$ 
With regard to the timing of violence $48.5 \%$ were happened during morning peak time when more rush is there in OPD, at registration counters, investigation labs etc. in the hospital in contrast to other studies which reveals that evening and night shifts demonstrate a significantly higher rate of aggression than the day shift $(10,11,12)$.

With respect to day of incident around $72.8 \%$ said that they don't remember the day when incident happened. But out of the remaining $27 \%$ who could remember the day, $15.4 \%$ said that it was Monday. Monday is considered to be the most stressful day of the week when it comes to risk factors for heart attack (13). But other study at Langley Memorial shows that there is no discernable trend in incidents occurring on a particular day of the week(14).

Study done in Riyadh South Arabia Nurses perceived shortage in security personnel (82\%), shortage in nursing staff $(63 \%)$, and unrestricted movement of patients in hospitals $(21.5 \%)$ as causes of their exposure to violence.(15)

Inadequate facilities like lack of waiting rooms, cafeteria, lack of trolleys in emergency, lack of medicines in the hospital, staff shortage drunken patients are the major factors, which have also been identified in various other studies. Poor soft skills in HCWs has also been identified as a contributing factor for the violence. (16)

$34 \%$ of group C employees said that there should be some restriction on the no of attendants to reduce the risk of violence, which have also been identified in various other studies $(2,17)$

In maximum incidents (92.6\%) of violence, perpetrators were the attendants or relatives of the patients as compared to study carried out on HCWs from an infectious disease hospital by Magnavita, et al Perpetrators were mainly the patients $(18,19)$. Where the perpetrator were patients it was found that maximum pts were either mentally or physically disabled.

It was found that maximum incidents (72\%) were seen in those who work in shifts, especially night shifts.

This is supported by a study done in China.(20) In contrast the study done in SKIMS revealed that Maximum instances of violence have been reported during evening hours.(11)

On analysis of the data in a Non COVID situation it immerges that the main cause of violence is overcrowding in Emergency Dept and OPD leading to increase in the waiting period which causes distress among patients and their attendants. The same sometimes lead to heated arguments with healthcare workers and may even culminate in physical violence. In addition, sometimes the deteriorating medical condition of the patient (specially in cancer patients) causes undue anxiety among the relatives of the patient and had led to violence.

However, in COVID situation the major reason for violence has emerged as the religious and cultural belief of the patient where they feel that they are unnecessarily been targeted. Healthcare workers and their families have also been ostracized by their neighbors because of their exposure to patients infected with Covid-19.(4) Second most common cause is the dissatisfaction among the patients due to poor quality of food being served to them in the healthcare facility. Poor dietary services have been identified a major cause of dissatisfaction among in patients in various studies.(21)

Lack of adequate security guards, amenities for patients and relatives and poor soft skill among healthcare workers are the common factors which are observed in the Non COVID as well as COVID situation.

\section{Conclusion}

The areas which are prone for violence are casualty, OPD and major risk factors identified are low staff patient ratio, less security, lack of patient amenities and lack of soft skills among HCWs. It is recommended that more staff should be appointed in areas with high work load, deployment of additional security guards in casualty and OPD, developing waiting areas \&amenity for patients and attendants, reducing $f$ waiting time and providing more information to patients and families and regular soft skill training for HCWs could reduce the rate of violence. The results of the study can aid in development of appropriate policy and strategies on workplace violence against health workers at hospitals and can also serve as the basis for future studies in the countryas workplace violence is one of the factors which can strongly reduce job satisfaction and the quality of working life of healthcare workers. Training should be given to the staff so that they can identify various indicators of violence such as STAMP (Staring, Change in tone, volume of voice, anxious behavior, mumbling \& incoherent speech of a patient or their relatives). Strong message should be 
conveyed in the society that safety and dignity of doctors at their work place is Nonnegotiable.

\section{Recommendation}

Identification of risk factors leading to increased work place violence against health care workers in hospital settings is essential and appropriate measures in form of adequate staffing, security and soft skills training need to be instituted.

\section{Limitation of the study}

Findings of the study are limited to the HCWs of public hospitals only. Private HCOs including nursing homes and clinics were excluded

\section{Relevance of the study}

The study has identified various risk factors associated with increased work place violence against health care workers. Suitable policy interventions can be undertaken based on the findings.

\section{Authors Contribution}

NG: Conceptualization of study, Drafting of manuscript. RG: Literature Search, Data acquisition, analysis, Manuscript preparation. DKS: Conceptualization of study, editing. SKG: Conceptualization of study, editing. PD: Data analysis, manuscript preparation, editing, review

\section{References}

1. work safe BC. Preventing violence in Health Care Five steps to an effective program. Workers' Compensation Board of British Columbia. 2005.

2. Hahn, S., Hantikainen, V., Needham, I., Kok, G., Dassen, T., \& Halfens, R. J. Patient and visitor violence in the general hospital, occurrence, staff interventions and consequences: a crosssectional survey. Journal of advanced nursing, 2012; 68(12), 2685-2699.

3. Programme J, Violence W, Sector H, Instruments E. Joint Programme on Workplace Violence in the Health Sector workplace violence in the health sector country case studies research instrument protocol sample design. 2003;1-5.

4. Pandey BV, BBC News D. Coronavirus: India doctors "spat at and attacked."

5. Programme J, Violence W, Sector H, Instruments E. International Council of Nurses ICN Joint Programme on Workplace Violence in the Health Sector Workplace V Iolence In The H Ealth S Ector. 2003;1-14.

6. Ruchi Garg,a Neeraj Garg,b,* D.K. Sharma c and SG. Low reporting of violence against health-care workers in India in spite of high prevalence. Med J Armed Forces India. Med J Arme.
7.

Chen WC, Hwu HG, Kung SM, Chiu HJ, Wang JD. Prevalence and determinants of workplace violence of health care workers in a psychiatric hospital in Taiwan. J Occup Health. 2008;50(3):28893. doi: 10.1539/joh.17132. Epub 2008 Apr 8. PMID: 18408350.[PubMed]

8. Kitaneh $\mathrm{M}$, Hamdan $\mathrm{M}$. Workplace violence against physicians and nurses in Palestinian public hospitals: a cross-sectional study. BMC Health Serv Res. 2012 20;12:469. doi: 10.1186/1472-6963-12-469. PMID: 23256893; PMCID PMC3541970.[PubMed].

9. Aaron W Cashmore12*, Devon Indig23, Stephen E Hampton234 DGH and BBJ. Workplace violence in a large correctional health service in New South Wales, Australia_ a retrospective review of incident management records. BMC Heal Serv Res_Full text_. 2012;

10. Moustafa A.F. Abbas, Lamiaa A. Fiala, Amira GE. Abdel Rahman AEF, Dept. Epidemiology of Workplace Violence against Nursing Staff in Ismailia Governorate, Egypt. J Egypt Public Heal Assoc [Internet]. 2010 [cited 2020 Dec 18];85(1\&2). Available from: http://www.epha.eg.net/pdf/n1-2-2010/2.pdf

11. J.Farooq, A Mustafa, D.Singh AT. Violence in hospitals. J Acad Hosp Adm. 2009;21(1):16-20.

12. Ariza-Montes A, Muniz NM, Montero-Simó MJ, Araque-Padilla RA. Workplace bullying among healthcare workers. Int J Environ Res Public Health. 2013 24;10(8):3121-39. doi: 10.3390/ijerph10083121. PMID: 23887621; PMCID: PMC3774428. [PubMed]

13. Sinatra DS. Heart Attack Risk Factors Rise on Mondays | Dr. Stephen Sinatra. heart health [Internet]; http://www. drsinatra.com/heart-attack-risk-factors-rise-on-mondays

14. Diane Brinton, RT Neil Boyd, LL.M Carol Cheveldave, B.Cospital LM. Workplace Violence Risk Assessment for Langley Memorial Hospital. Inc., HConducted by Advance Workplace Management. 2001. 25.

15. Mohamed AG. Work-related assaults on nursing staff in riyadh, saudi arabia. J Family Community Med. 2002 Sep;9(3):51-6. PMID: 23008680; PMCID: PMC3430167.[PubMed]

16. Balamurugan $G$, Treesa $T$, Nandakumar P. Patients ' violence towards nurses : A questionnaire survey. 2012;1(1):1-7.

17. Health $P$, Branch $S$, Health $O$, Program S. Workplace violence and Prevention in New Jersey hospital Emergency Departments.

18. Lönnroos, John AT, Final. Tanzanian nurses exposure and experience of violence. Department of Public Health and Caring Sciences. 2013.

19. Gerberich SG. An epidemiological study of the magnitude and consequences of work related violence: the Minnesota Nurses' Study. Occup Environ Med [Internet]. 61(6):495-503. Available from: http://oem.bmj.com/content/61/6/495.full

20. Zeng JY, An FR, Xiang YT, Qi YK, Ungvari GS, Newhouse R, Yu DS, Lai KY, Yu LY, Ding YM, Tang WK, Wu PP, Hou ZJ, Chiu HF. Frequency and risk factors of workplace violence on psychiatric nurses and its impact on their quality of life in China. Psychiatry Res. $2013 \quad 15 ; 210(2): 510-4 . \quad$ doi:10.1016/j.psychres. 2013.06.013. Epub 2013 Jul 11. PMID: 23850435.[PubMed]

21. Gupta SK, Garg N, Mahesh R. Patient Satisfaction Survey at a Tertiary Care Speciality Hospital. Int J Res Found Hosp Healthc Adm. 2014;2(2):79-83.

\section{Tables}

TABLE 1 INCIDENTS OF VIOLENCE AMONG HEALTH CARE WORKERS ( $N=394$ )

\begin{tabular}{|l|l|l|l|l|l|l|}
\hline Area & Doctors $n=123$ & & Nurses $n=125$ & Group $\mathrm{C} n=146$ \\
& Respondents & Experienced & Respondents & Experienced & Respondents & Experienced \\
\hline Casualty & $32(26.0 \%)$ & $18(56.3 \%)$ & $33(26.4 \%)$ & $22(66.7 \%) \mathrm{P}=.002$ & $10(6.9 \%)$ & $6(60 \%)$ \\
\hline
\end{tabular}




\begin{tabular}{|l|l|l|l|l|l|l|}
\hline OPD & $35(28.5 \%)$ & $15(42.9 \%)$ & $18(14.0 \%)$ & $8(44,4 \%)$ & $21(14.4 \%)$ & $7(33.3 \%)$ \\
\hline Wards & $39(31.7 \%)$ & $19(48.7 \%)$ & $50(40.2 \%)$ & $22(44.0 \%)$ P =.002 & $108(74 \%)$ & $7(6.5 \%)$ \\
\hline Daycare & $10(8.1 \%)$ & $3(30 \%)$ & $5(4.0 \%)$ & & 0 & $3(2.1 \%)$ \\
\hline ICU & $7(5.7 \%)$ & $3(42.9 \%)$ & $19(15.2 \%)$ & $3(15.8 \%)$ & $4(2.7 \%)$ & $2(50 \%)$ \\
\hline
\end{tabular}

\section{Figures}

FIGURE 1 AREAS WISE DISTRIBUTION OF HOSPITAL WITH RESPECT TO INCIDENTS OF VIOLENCE

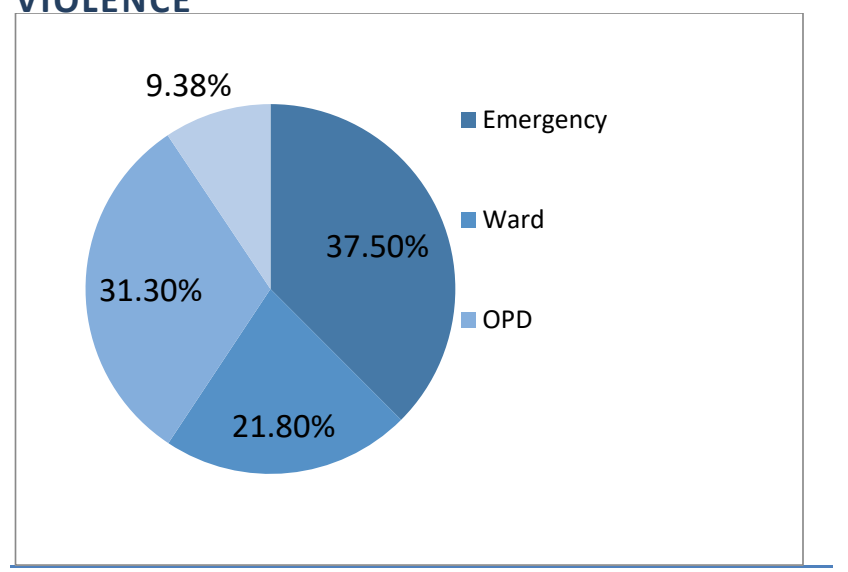

FIGURE 2 INCIDENTS OF VIOLENCE AS PER DAY OF THE WEEK

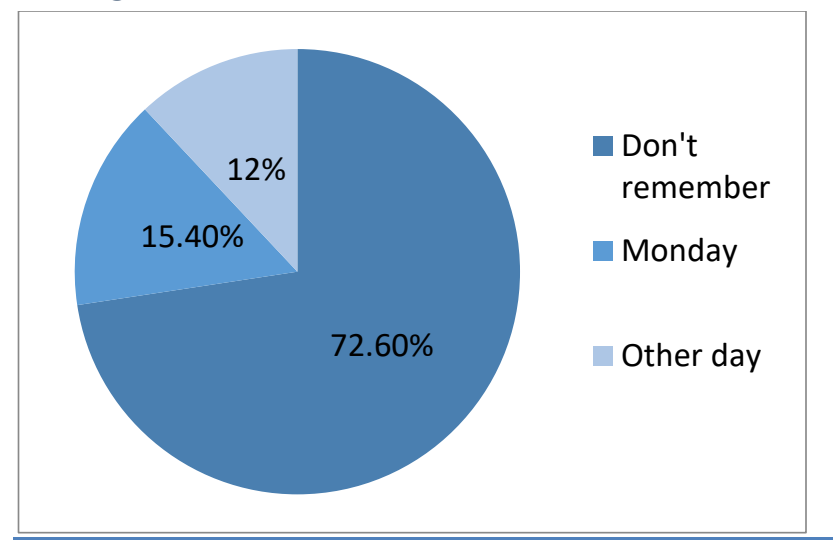

\section{FIGURE 3 INCIDENTS OF VIOLENCE AS PER} THE CATEGORY OF PATIENT

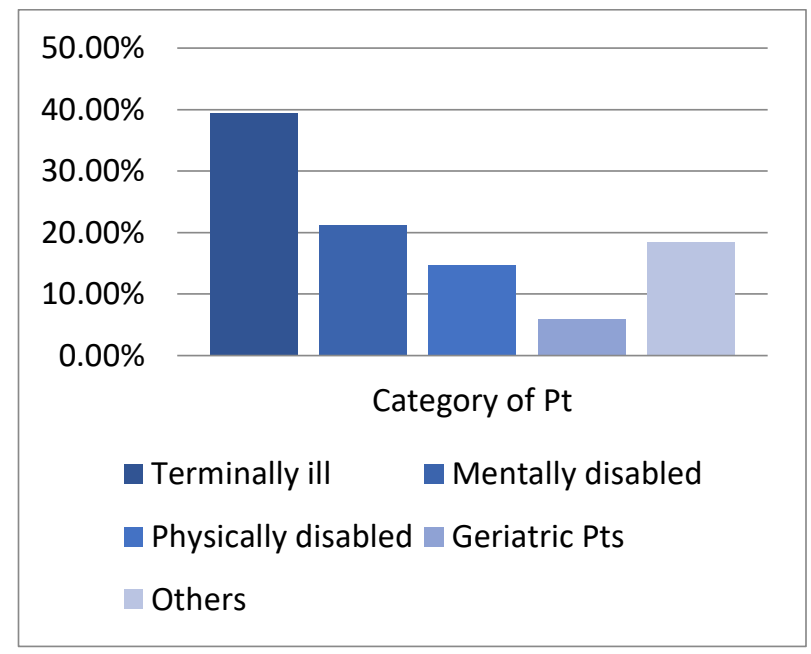

\section{FIGURE 4 CAUSES OF VIOLENCE DURING NON COVID TIME}

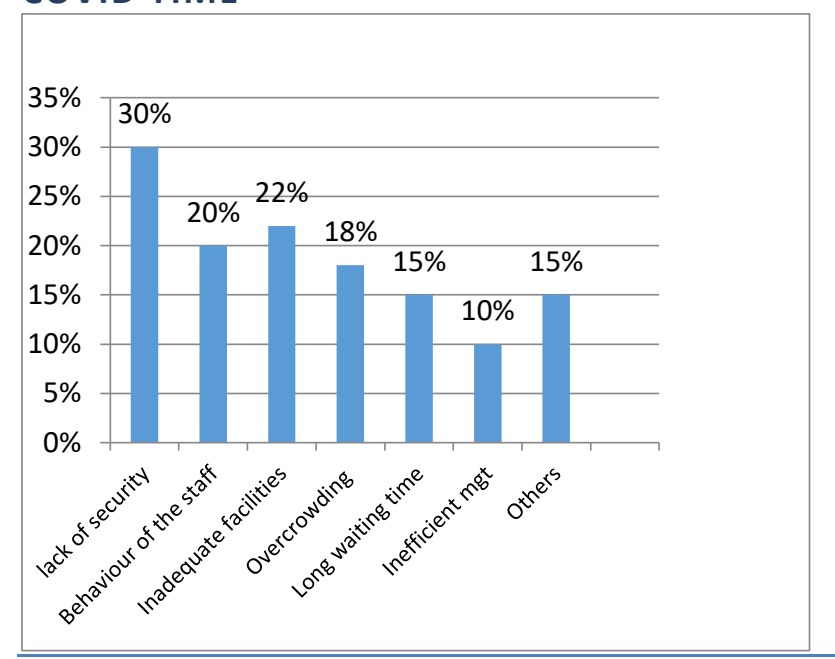

\section{FIGURE 5 CAUSES OF VIOLENCE DURING COVID}

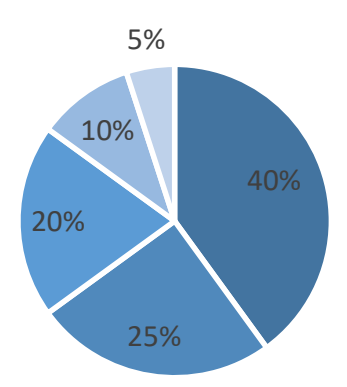

\footnotetext{
- Religious cultural belief - Poor dietar service

- Poor amenities = Lack of security

- Poor soft skills
} 